\title{
1 CFD model for the performance estimation of open volumetric receivers and comparison with experimental data
}

\author{
Hannes Stadler ${ }^{\mathrm{a}}$, Daniel Maldonado ${ }^{\mathrm{b}}$, Matthias Offergeld ${ }^{\mathrm{a}}$, Peter Schwarzbözl ${ }^{\mathrm{b}}$, Johannes Trautner $^{\mathrm{c}}$ \\ ${ }^{a}$ DLR Institute of Solar Research, Prof.-Rehm-Straße 1, 52428 Jülich, Germany \\ ${ }^{b}$ DLR Institute of Solar Research, Linder Höhe, 51147 Köln, Germany \\ ${ }^{c}$ Kraftanlagen München GmbH, Ridler Straße 31 c, 80339 München, Germany
}

\section{Abstract}

Obtaining reliable information on the thermal performance of a receiver in a solar thermal power plant during the design phase is essential for optimisation purposes and for the determination of the economic performance of the entire power plant. In open volumetric receivers, where the heat transfer circuit is open to the environment, this task is particularly challenging due to the influence of convection phenomena on the air return ratio and thus the heat losses. These losses can only be estimated by means of CFD simulations, however, since the small scale absorber structure is several orders of magnitude smaller than the receiver itself, the required computational grid becomes too large to be economically viable.

In this paper a modeling approach is presented, which for the first time allows the efficient simulation of the entire receiver including the flow in front of and around the receiver while at the same time considering internal heat transfer within the absorber. A set of boundary conditions has been developed for the absorber surface of open volumetric receivers in which the characteristic behaviour of the aborber is modeled without the need of detailed resolution of the absorber structure. The model has been validated against new measurements at the solar tower Jülich. Moreover, in comparison with literature data of air return ratio measurements a very good agreement was found.

A characteristic map of the receiver efficiency has been simulated showing peak efficiencies of the open volumetric receiver of the solar tower Jülich of $70.9 \%$ at a hot air temperature of $650{ }^{\circ} \mathrm{C}$ and $75.4 \%$ at $450{ }^{\circ} \mathrm{C}$. The model can now be used for the assessment of design concepts for commercial power plants.

Keywords: open volumetric receiver, CFD simulation, efficiency, air return ratio

\section{Introduction}

The efficiency of the receiver of a solar thermal power plant has a big influence on the yield of the power plant. It is also directly coupled to the layout of the heliostatfield. Thus, it is of utmost importance to have reliable information on the receiver performance already during the design phase of the power plant. The two major factors influencing the efficiency of the receiver are the radiative and the convective losses. While the radiative losses can usually be estimated to a reasonable accuracy, the convective losses are somewhat more difficult to be determined. For external receivers numerous correlations have been derived in the past (Siebers and Kraabel, 1984; Christian and Ho, 2012; Uhlig et al., 2016) and cavity receivers are investigated thoroughly (Clausing, 1981; Flesch et al., 2015; Siegrist et al., 2018). Independent of the outer geometry of the receiver, these findings cannot easily be adapted to open volumetric receivers. Here, the air, which is still warm after the steam generator, is returned to the receiver. However, since it is an open system this return air partly mixes with ambient air which reduces the heat recovery. Therefore, the convective losses of this type of receiver is dominated by the air return ratio and

Email address: hannes.stadler@dlr.de (Hannes Stadler) thus the air return mechanism. Marcos et al. (2004) evaluated various designs of the air return system and highlighted the significance of high air return ratios for the increase of the receiver efficiency.

According to a review by Ávila-Marín (2011) air return ratios in the range of 40 to $60 \%$ are state of the art. More recently, Stadler et al. (2017) and Tiddens et al. (2017) have presented measurements of the air return ratio at the solar tower Jülich in the range of 50 to $70 \%$. Overall receiver efficiencies are reported in a range from 48 to $80 \%$ (Ávila-Marín, 2011) and 50 to $60 \%$ (Ho and Iverson, 2014). The efficiencies reported in these reviews were mainly evaluated from experimental data from prototype receivers or are based on absorber efficiencies.

Pitot de la Beaujardiere and Reuter (2018) have presented a review on the modeling of open volumetric receivers. Several approaches exist for the modeling of absorber efficiencies. For example, Wu et al. (2011) as well as Wu and Wang (2013) have developed detailed models for mesh-type absorbers and Capuano et al. (2016) have reviewed approaches which are suitable for HiTRec-type absorbers. These models take the incoming radiation, the inlet temperature in front of the absorber, and the mass flow as input and return the hot air temperature at the outlet of the absorber based on heat transfer calculations. In this type of model the heat transfer to the return air flow is neglected 


\section{Nomenclature}

\section{Acronyms}

HiTRec High Temperature Receiver

\section{Greek Symbols}

$\gamma \quad$ identifier for return air inlet cells (-)

$\varepsilon \quad$ emissivity (-)

$\zeta \quad$ pressure drop coefficient $(-)$

$\eta \quad$ receiver efficiency (-)

$\varrho \quad$ fluid density $\left(\mathrm{kg} / \mathrm{m}^{3}\right)$

$\sigma \quad$ Stefan-Boltzmann constant $\left(5.67 \times 10^{-8} \mathrm{~W} /\left(\mathrm{m}^{2} \mathrm{~K}\right)\right)$

\section{Roman Symbols}

A mesh face surface area

$a_{0-7} \quad$ regression coefficients

$A R R \quad$ air return ratio

$b_{0-2} \quad$ regression coefficients

$G \quad$ irradiance $\left(\mathrm{W} / \mathrm{m}^{2}\right)$

$\dot{H} \quad$ enthalpy flow (W)

$h \quad$ specific enthalpy $(\mathrm{J} / \mathrm{kg})$

$J \quad$ radiosity $\left(\mathrm{W} / \mathrm{m}^{2}\right)$

$\dot{m} \quad$ mass flow $(\mathrm{kg} / \mathrm{s})$

$\vec{n} \quad$ patch normal vector (-)

$p \quad$ pressure $(\mathrm{Pa})$

$P_{\text {air }} \quad$ air power $(\mathrm{W})$

$\dot{Q} \quad$ radiative heat flux $(\mathrm{W})$

$T \quad$ temperature (K)

$\vec{U} \quad$ velocity $(\mathrm{m} / \mathrm{s})$

\section{Subscripts}

$i \quad$ patch cell index

$j \quad$ agglomerate index

abs absorber

design design point

fan at fan

h hot air

inc incident radiation at receiver

$\mathrm{p} \quad$ patch surface

$\mathrm{r} \quad$ return air

rad radiation

rec receiver as the focus is on the radiation absorbtion and emission as well as the heat transfer to the hot air flow.

In a more complex approach by Ahlbrink et al. (2009a) the entire receiver is modeled taking into account the heat flux and the mass flow distribution across the absorber surface. However, the air return ratio was considered constant across the absorber surface neglecting the interaction between individual absorber modules of the HiTRec concept.

Maldonado Quinto (2016) has analysed the interaction between the hot air and the return air flows by means of CFD simulations of a single absorber. He has shown a minimum of the air return ratio at the absorber for a ratio of the return air mass flow to the hot air mass flow of 1 . Moreover, he has shown that a reduction of the return air momentum by increasing the surface area is beneficial for the air return ratio.

The interaction between individual absorbers was investigated by Roldán et al. (2016) in a 2D CFD simulation and with a full 3D model by Maldonado Quinto (2016) with the result, that for an arrangement of several absorber modules placed on top of each other the overall air return ratio was reduced by about $5 \%$-points with respect to the single absorber module. This behaviour is due to the complex interaction of the return air flow with the ambient and highlights the necessity to consider the entire receiver together with the ambient flow for the determination of the efficiency. Thus, it is essential to build a numerical model in which the complex flow phenomena in front of the absorber are taken into consideration and which is computationally efficient enough to be used for the analysis of receivers of commercial scale.

\section{The Solar Tower Jülich}

The largest solar thermal power plant with open volumetric receiver built so far is the solar tower Jülich with a thermal power output of $7 \mathrm{MW}$ (Koll et al., 2009). Up to now, only one other power plant with open volumetric receiver has been built thereafter in Daegu, Korea with a thermal power of $200 \mathrm{~kW}$ (Jang et al., 2012). For the development of the numerical model the solar tower Jülich will thus serve as reference geometry and the simulation results will be compared to data obtained from measurements at it.

The basic design of the Solar Tower Jülich has previously been described in Stadler et al. (2017) and is repeated here for clarity, see fig. 1 . The receiver is centred at $55 \mathrm{~m}$ above ground level and has an aperture of approximately $23 \mathrm{~m}^{2}$. The air that is heated in the receiver (1) is used to produce steam in a heat recovery steam generator (2) or is stored in the thermal energy storage (3). Thereafter it is returned to the receiver in order to recycle its residual heat (4). Thereby it is also used to cool the receiver metal support structure to prevent overheating. The air is then blown out in between individual absorber modules as has been described by Ahlbrink et al. (2013), see also fig. 2 . 


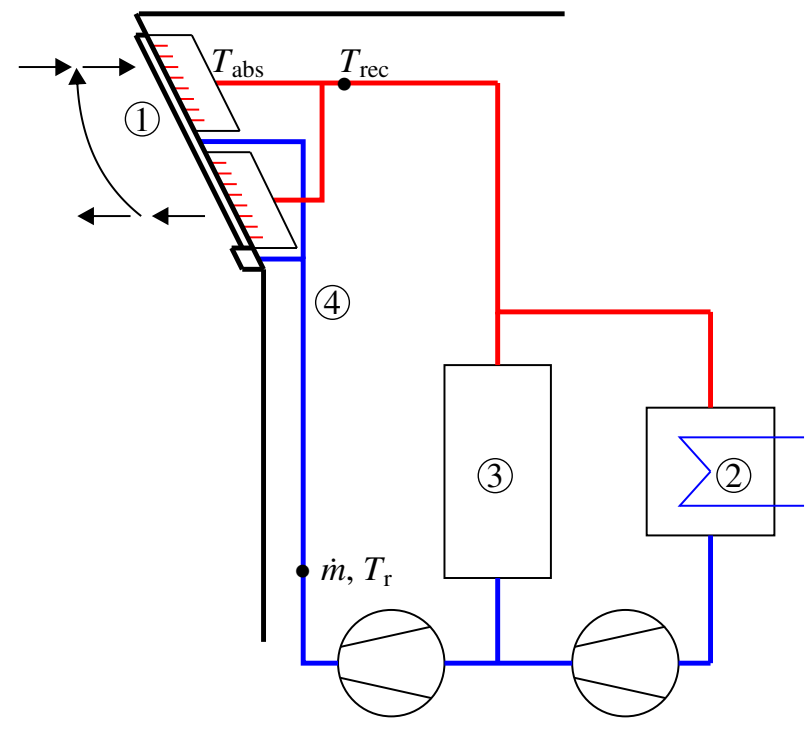

Figure 1: Basic design of a central receiver solar power plant with open volumetric receiver, 1 : receiver, 2 : heat recovery steam generator, 3 : thermal energy storage, 4: air return system.

Outside the receiver the return air mixes with ambient air so that only a part of it is sucked back in. The air flowing through individual absorber modules is heated to the temperature $T_{\text {abs }}$. It is then collected in a single hot air pipe where the mixing temperature $T_{\text {rec }}$ is reached.

The receiver itself consists of 1080 square absorber modules with a gap of a few millimetres in between them as shown in fig. 2. The design mass flow distribution is adjusted for every absorber module to follow the distribution of the design intercept radiation (cf. Ahlbrink et al. (2013)).

\section{Measurements}

As indicated in the review by Pitot de la Beaujardiere and Reuter (2018), hardly any data of large scale receivers are available for the validation of numerical models. Thus, measurements have been conducted at the solar tower Jülich which can be used as benchmark. For the calculation of the receiver efficiency $\eta$ according to eq. 1 the temperatures of the hot air and the return air $T_{\mathrm{h}}$ and $T_{\mathrm{r}}$, respecitvely as well as the total air massflow $\dot{m}$ and the incident power $\dot{Q}_{\text {inc }}$ have to be measured.

$$
\eta=\frac{P_{\mathrm{air}}}{\dot{Q}_{\mathrm{inc}}}=\frac{\dot{H}_{\mathrm{h}}-\dot{H}_{\mathrm{r}}}{\dot{Q}_{\mathrm{inc}}}=\frac{\dot{m}}{\dot{Q}_{\mathrm{inc}}} \cdot\left(h\left(T_{\mathrm{h}}\right)-h\left(T_{\mathrm{r}}\right)\right)
$$

The mass flow has been measured with a ultrasonic flow metre with an accuracy of $\pm 1 \%$. Both, the return air and the hot air temperature have been determined by taking the average of sets of five type $\mathrm{N}$ thermocouples. The return air temperature was measured next to the mass flow measurement as indicated in fig. 1 and the hot air temperature right after the collection of the individual absorber flows.

The flux density distribution was measured by a revised and enhanced method based on the reflection method presented by Göhring et al. (2011). The reflection off the absorber is recorded with a camera and this image is corrected for the spatially unequal reflective properties of the absorber material. With this method high quality flux distribution maps can be obtained.

For the evaluation of the receiver efficiency stationary operating points have been sought and the respective parameters have been averaged over a period of $10 \mathrm{~min}$.

Measurements of the air return ratio have been presented earlier (Stadler et al., 2017) and will be used for the verification of the numerical model.

\section{Modeling}

CFD simulations have been carried out using the opensource CFD-code OpenFOAM version 4.1. The challenge in modeling open volumetric receivers is the span over several orders of magnitude in the size of individual absorber channels (in the order of $1 \mathrm{~mm}$ ) and the size of the entire receiver which is in the order of $10 \mathrm{~m}$. This results in very large mesh sizes in the order of $10^{9}$ mesh elements which is not suitable for engineering simulations. Therefore, the absorber structure has to be modeled without resolving all geometric details. To do so, a set of appropriate boundary conditions has to be developed for the absorber surface which has to fulfil three functions: firstly, it serves as outflow boundary for the air which is heated up in the absorber, secondly, it serves as inlet boundary for the return air flow, and thirdly, the radiative transfer equation has to be solved in order to guarantee the conservation of energy.

The general approach is visualised in fig. 2. The performance of the absorber structure itself, that is the radiation absorbtion and the heat transfer from the absorber material to the air, is modeled in a 1D-FEM model and stored in characteristic maps, one for the temperature of the return air on the boundary of the CFD domain (i.e. the patch) $T_{\mathrm{p}, \mathrm{r}}$ and one for the hot air temperature behind the absorber $T_{\mathrm{h}}$. Within the temperature boundary condition these values are read from the characteristic maps and further processed.

\subsection{Geometric Representation of Absorber Structure}

Instead of resolving individual absorber modules and the channels in between them, the entire absorber is treated as a single patch with a smooth surface. A certain number of patch cells is then pooled together in separate agglomerates. A fraction of the cells in the centre of every agglomerate is then defined as return air inlet (variables referring to these cells carry the index r) whereas the remainder of every agglomerate serves as outlet out of the computational domain for the hot air (index h). Starting with a single cell in the centre of the agglomerate defined as inlet cell, further neighbouring cells are subsequently added until the area fraction of the inlet section reaches the same ratio as in the original receiver. Thus, the momenta of the incoming and the outgoing fluid streams are modeled corresponding to the original. 


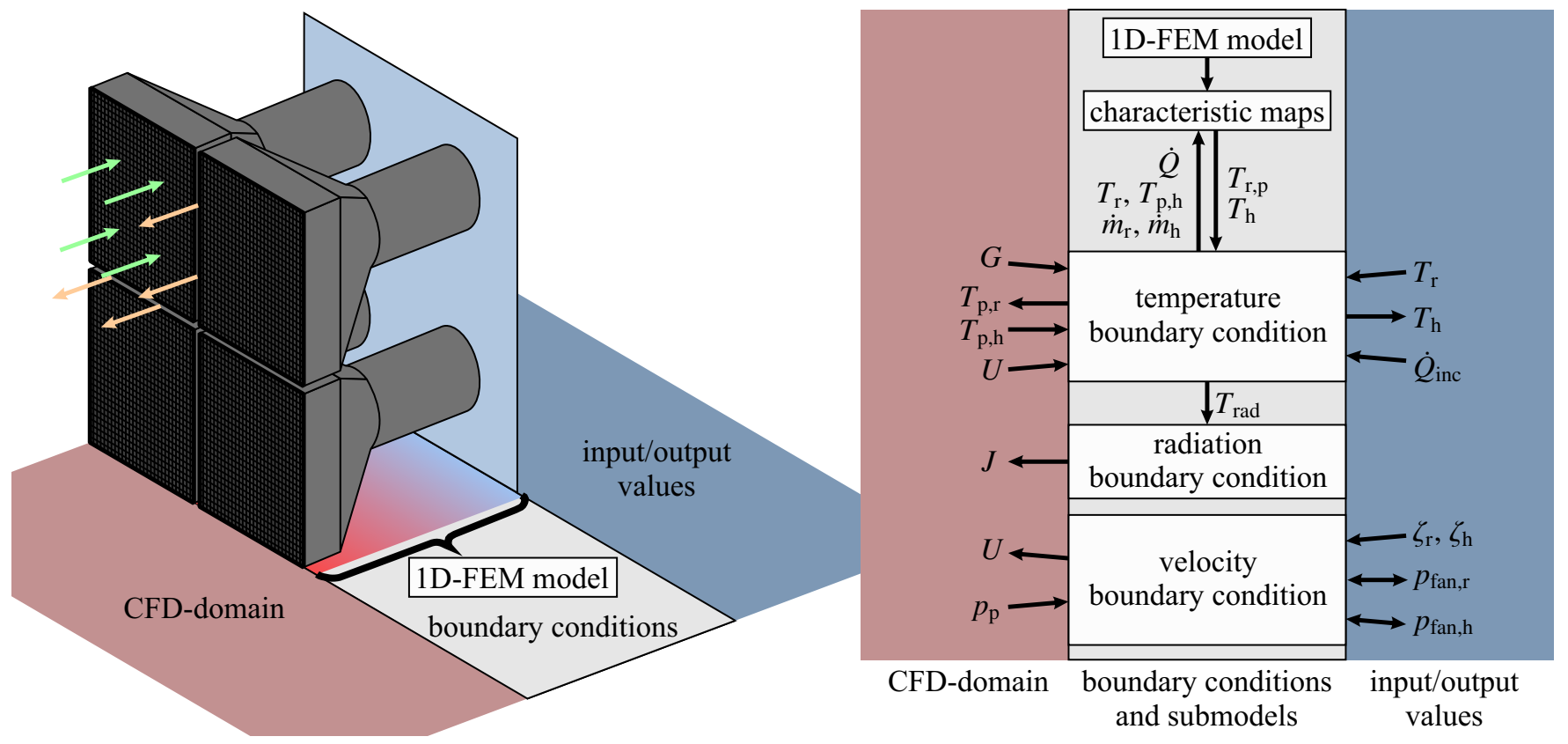

Figure 2: Schematic drawing of absorber structure on the left side. The return air gaps between individual absorber modules are shown with orange arrows marking the return air flow and the gree arrows marking the flow into the absorber. On the right side the flow diagram of the multi-level modeling approach with respective input and output parameters is shown. The meaning of the parameters is defined in section 4.

\subsection{Characteristic Maps of Absorber Performance}

For the calculation of the characteristic maps of the absorber performance a one dimensional model of the absorber modules is used as described by Ahlbrink et al. (2009b). On the basis of a typical incident radiation, that is the angular distribution of the incident flux, the absorption in the absorber channels is evaluated. This heat flux is then used as a boundary condition for the calculation of the heat transfer between the absorber structure and the fluid flow. Furthermore, after leaving the honeycomb structure of the absorber the heat exchange between the hot air and the return air is modeled as well. In the characteristic maps the hot air temperature $T_{\mathrm{h}}$ and the return air temperature after leaving the absorber $T_{\mathrm{p}, \mathrm{r}}$ are stored as a function of the incident radiation $\dot{Q}$, the inlet return air temperature $T_{\mathrm{r}}$, the patch temperature $T_{\mathrm{p}, \mathrm{h}}$, and the mass flows of the hot air and the return air $\dot{m}_{\mathrm{h}}$ and $\dot{m}_{\mathrm{r}}$, respectively.

Unlike the hot air temperature measured and used for power plant operation in the solar tower Jülich, the hot air temperature analysed in the CFD simulations thus represents the temperature directly after the absorbers.

While the characteristics used in the current model have been calculated for the HiTRec honeycomb structure, characteristics for other structures like foams, wire meshes (Fend et al., 2004), or printed structures (Capuano et al., 2017) can easily be integrated in the boundary condition.

\subsection{Boundary Conditions for Velocity Field}

For the calculation of the velocity on the boundary patch a numerical approach resembling the real setup has been chosen. The mass flow through the absorber is a result of the difference between the ambient pressure and the pressure inside the absorber. In order to obtain a desired mass flow distribution, orifices with adapted diameters are integrated in the flow path (Ahlbrink et al., 2013). This behaviour is modeled on the CFD side by introducing pressure loss coefficients for both flow directions, return air and hot air, $\zeta_{\mathrm{r}}$ and $\zeta_{\mathrm{h}}$ which results in an artificial pressure drop. The distribution of the pressure loss coefficients is mapped on the computational grid and the velocity is then calculated according to the following equation:

$$
\begin{array}{r}
\vec{U}=\vec{n}\left(\sqrt{2 \cdot \frac{\left(p_{\mathrm{p}}-p_{\mathrm{fan}, \mathrm{h}}\right)}{\zeta_{\mathrm{h}} \varrho_{\mathrm{p}}} \cdot(1-\gamma)}\right. \\
\left.-\sqrt{2 \cdot \frac{\left(p_{\mathrm{fan}, \mathrm{r}}-p_{\mathrm{p}}\right)}{\zeta_{\mathrm{r}} \varrho_{\mathrm{r}}}} \cdot \gamma\right)
\end{array}
$$

Herein, $\zeta$ is the pressure drop coefficient, $\varrho$ is the density, $p$ is the pressure, $\vec{n}$ is the normal vector of the patch, and $\gamma$ is the field describing the return air outlet cells $(\gamma=1$ for return air cells and $\gamma=0$ for hot air cells). The indices 'p' stand for the patch value as compared to the internal values 'fan', see fig. 2 . The internal values are additionally distinguished for the return air and the hot air.

The internal pressure values $p_{\mathrm{fan}, \mathrm{h}}$ and $p_{\mathrm{fan}, \mathrm{r}}$ are equal over the entire patch, but are iteratively adjusted by means of a PIcontroller so that the temperature of the hot air as it is determined in the temperature boundary condition reaches the desired value and so that the final mass flow of the return air matches the value of the hot air. 


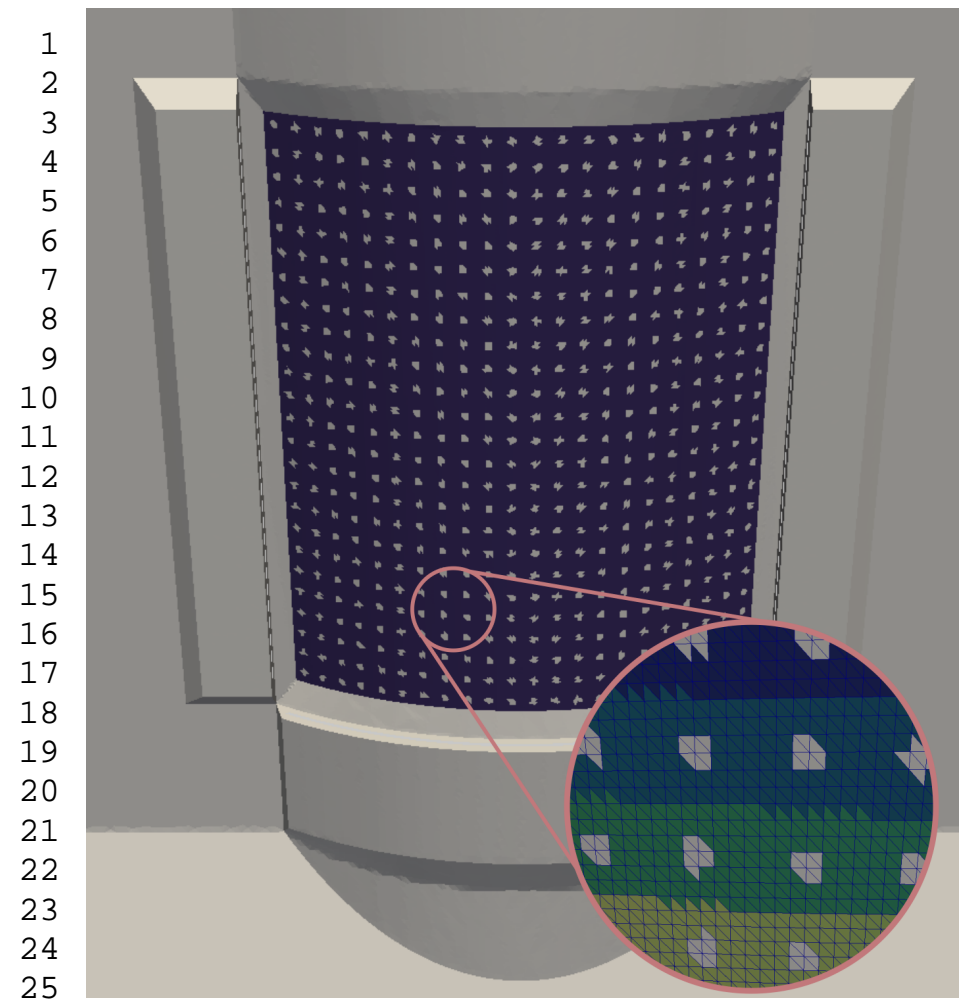

26

27 summation over every agglomerate cell $i$ :

$$
P_{\mathrm{air}, j}=\sum_{i} \dot{m}_{i} \cdot\left(h\left(T_{\mathrm{h}, j}\right) \cdot\left(1-\gamma_{i}\right)-h\left(T_{\mathrm{r}, j}\right) \cdot \gamma_{i}\right)
$$

The total air power is determined by summation over all agglomerates:

$$
P_{\text {air }}=\sum_{j} P_{\mathrm{air}, j} .
$$

The difference between the irradiance $G$ and the energy transferred to the air flows, return air and hot air, is equivalent to the radiosity $J$ which comprises both, reflection and emission:

$$
J_{i}=G_{i}-P_{\mathrm{air}, j} \cdot \frac{A_{i}}{A_{j}} .
$$

If a radiation model is used, the radiosity can be used to calculate an effective radiation temperature $T_{\text {rad }}$ which is then used in the radiation boundary condition. Otherwise this term is only of informative nature.

$$
T_{\mathrm{rad}}=\sqrt[4]{\frac{J}{\sigma \varepsilon}}
$$

\subsection{Boundary Condition for Radiation View Factor Model}

If, next to the incident radiation from the heliostat field, radiative heat transfer is incorporated in the simulation, a boundary condition is needed in which the radiative losses from the absorber surface are determined. With the radiation temperature $T_{\text {rad }}$ calculated in the temperature boundary condition the effective radiative losses are evaluated.

\subsection{Computational Grid}

The computational domain for the current investigation had a square base area with $50 \mathrm{~m} \times 50 \mathrm{~m}$ and a height of $75 \mathrm{~m}$ starting from the ground and ranging to $15 \mathrm{~m}$ above the tower which was horizontally centred in the domain. Full tetrahedral grids have been used. Since the absorber is an inflow/outflow boundary condition and the surrounding radiation shield was modeled adiabatic, no inflation layers were used.

Due to the new modeling approach a conventional grid independence study is not sufficient for the estimation of the discretisation error. The higher the chosen number of agglomerates the better the model reflects the true absorber structure. However, due to the surface discretisation there is a limit. Therefore, next to a variation of the grid size with three grids ranging from 4.5 million to 9.9 million elements with a resolution on the absorber surface ranging from $4 \mathrm{~cm}$ to $2 \mathrm{~cm}$ also the effect of the number of agglomerates and of the area fraction of the inlet cells has been analysed.

From the results presented in table 1 it becomes apparent, that the grid size and the area fraction of the inlet cells has no markable influence neither on the air return ratio nor on the efficiency. Only the number of agglomerates has a positive effect on both, the air return ratio and the efficiency. Moreover, any increase of the efficiency is directly proportional to an increase of the air return ratio. Therefore, it is sufficient for the grid 
Table 1: Results of the mesh independence study.

\begin{tabular}{llllllc}
\hline $\begin{array}{l}\text { no. of } \\
\text { cells }\end{array}$ & $\begin{array}{l}\text { abs. } \\
\text { res. }\end{array}$ & $\begin{array}{l}\text { no. of } \\
\text { aggl. }\end{array}$ & frac & s/t & ARR & $\eta$ \\
\hline $4.5 \mathrm{mio}$ & $4 \mathrm{~cm}$ & 550 & $8.9 \%$ & $\mathrm{~s}$ & $59.8 \%$ & $68.8 \%$ \\
$5.9 \mathrm{mio}$ & $3 \mathrm{~cm}$ & 550 & $8.5 \%$ & $\mathrm{~s}$ & $61.3 \%$ & $69.8 \%$ \\
$9.9 \mathrm{mio}$ & $2 \mathrm{~cm}$ & 550 & $8.5 \%$ & $\mathrm{~s}$ & $60.6 \%$ & $69.3 \%$ \\
$5.9 \mathrm{mio}$ & $3 \mathrm{~cm}$ & 320 & $8.1 \%$ & $\mathrm{~s}$ & $55.0 \%$ & $68.2 \%$ \\
$5.9 \mathrm{mio}$ & $3 \mathrm{~cm}$ & 700 & $8.5 \%$ & $\mathrm{~s}$ & $63.1 \%$ & $70.2 \%$ \\
$5.9 \mathrm{mio}$ & $3 \mathrm{~cm}$ & 550 & $7.6 \%$ & $\mathrm{~s}$ & $60.8 \%$ & $69.7 \%$ \\
$5.9 \mathrm{mio}$ & $3 \mathrm{~cm}$ & 550 & $7.9 \%$ & $\mathrm{~s}$ & $59.9 \%$ & $69.4 \%$ \\
$5.9 \mathrm{mio}$ & $3 \mathrm{~cm}$ & 550 & $8.5 \%$ & $\mathrm{t}$ & $\mathrm{nd}$ & $69.7 \%$ \\
\hline
\end{tabular}

abs. res.: absorber resolution

no. of aggl.: number of agglomerates

frac: average area fraction of inlet cells per agglomerate

$\mathrm{s}$ : steady state; t: transient

independence study to analyse the influence of the number of agglomerates on the air return ratio.

The increase of the air return ratio with increasing number of agglomerates is significant. However, there is a limit in further refinement of the agglomerates as for the stability of the simulation it is advisable not to have single cells as inlet surrounded by outlet cells. For the medium case with 550 agglomerates every agglomerate consists of around 80 to 90 mesh faces and in every agglomerate about 6 to 7 faces are marked as inlet cells for the return air.

For the current investigation the mesh with a total of 5.9 million grid elements and a size on the absorber surface of $3 \mathrm{~cm}$ was chosen. In total, 550 agglomerates have been defined so that compared to the original geometry about two absorber modules are combined in one agglomerate. As will be seen later, this choice resulted in a good, in some points conservative, estimation of the air return ratio.

For this case also a transient simulation has been carried out in order to analyse the influence of transient effects on the solution correctness. No markable difference between the steadystate and the transient simulation is apparent so that for the further study steady-state simulations are considered.

From this grid study the discretisation error can be estimated as the spread of the simulations with varying grid parameters. For the simulated efficiency it lies in the range of $\pm 2 \%$ and for the simulated air return ratio it lies in the range of $\pm 5 \%$.

\subsection{Simulation Setup}

In order to obtain a characteristic map of the receiver performance, simulations have been conducted with varying hot air temperatures $\left(450{ }^{\circ} \mathrm{C}, 550{ }^{\circ} \mathrm{C}, 650^{\circ} \mathrm{C}\right.$, and $\left.700^{\circ} \mathrm{C}\right)$ and load conditions ranging from $20 \%$ to $100 \%$. The incident flux for all these simulations was based on the design flux distribution and was scaled according to the load condition.

In addition, setups run during the measurements of the receiver performance have been simulated as well whereby the mass flow was fixed in the boundary condition instead of the hot air temperature.
The steady-state simulations have been started from a common initial solution. After about 1000 simulation steps the desired temperature was reached and shortly thereafter the air power reached a constant level as well. Due to the fluctuating nature of natural convection phenomena the simulation was run for a total of 10000 simulation steps and average values of the last 3000 iteration steps have been used for further analysis. Ideally, all simulations should have been carried out transient instead of steady state. However, a transient simulation with a sample case showed that the difference between the transient solution and the steady state solution is well below the uncertainty of the meshing error and thus the results of the steady state simulation can be used for further analysis.

For the evaluation of the air return ratio, a subsequent simulation with a passive scalar was run. The passive scalar has a value of 1 in the inlet of the return air (as seen from the computational domain) and 0 on all other inlets. As a consequence, the mass flow averaged value of the passive scalar on the actual absorber surface (air outlet for the compuational domain) gives the concentration of the return air and thus the air return ratio.

\section{Results}

Figure 4 shows exemplarily the distribution of the patch temperature $T_{\mathrm{p}}$. For a hot air temperature of $650{ }^{\circ} \mathrm{C}$ and $100 \%$ a quite even temperature distribution around $450{ }^{\circ} \mathrm{C}$ can be seen with two regions at the upper outer edges of the receiver reaching values close to $600{ }^{\circ} \mathrm{C}$. At the lower edge the temperature is close to the ambient temperature. The return air cells where the temperature is set according to the characteristic maps stand out relative to the surrounding temperatures with higher values all across the receiver.

In fig. 5 the distribution of the return air concentration on the absorber is shown with a slice through the fluid in front of it again for a hot air temperature of $650{ }^{\circ} \mathrm{C}$ and $100 \%$ load. On the absorber the return air concentration is equivalent to the air return ratio. The return air concentration (and thus the $A R R)$ exhibits the same general pattern as the patch temperature. It varies between $40 \%$ and $100 \%$ while at the lower edge of the absorber the return air concentration is close to zero. From the slice it can be seen that high return air concentrations are reached also at quite some distance from the absorber. Moreover, the streamlines projected onto the slice highlight the strong mixing effects as well the convective flow to the top carrying away part of the return air.

In Stadler et al. (2017) it was shown, that the air return ratio primarily depends on the mass flow. In fig. 6 results from the simulation are plotted over the mass flow. The graph is truncated at a maximum mass flow of $15 \mathrm{~kg} / \mathrm{s}$ since higher mass flows are technically not feasible at the solar tower Jülich. It can be seen, that all data follow the same trend independent of the hot air temperature. Thus, a single power law regression for all data according to eq. 7 was determined and is included in the graph.

$$
A R R=a_{0}+a_{1} \cdot \dot{m}^{-a_{2}}
$$




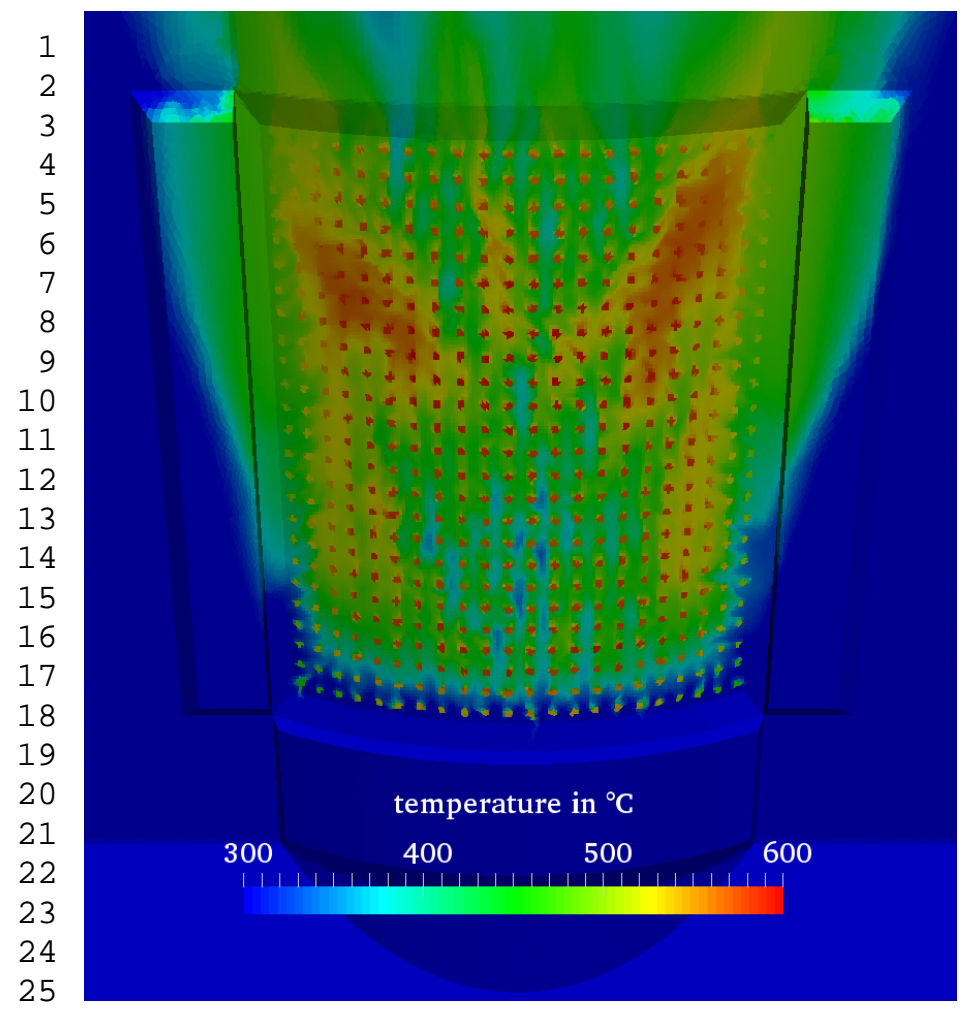

26

27

28

29

30

31

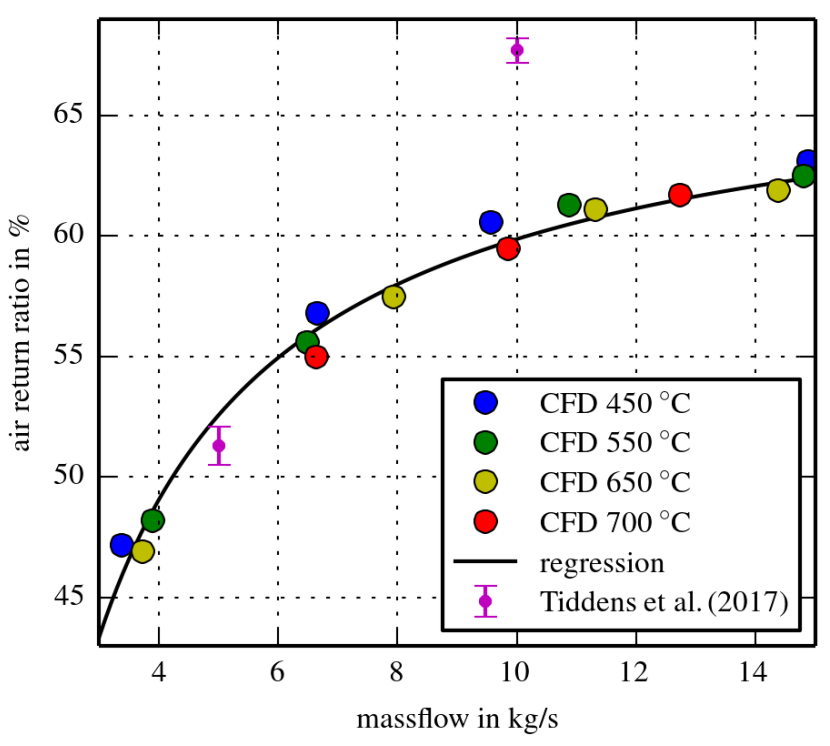

Figure 6: Simulation results for the air return ratio and comparison to experimental data taken from Stadler et al. (2017). The experiments were carried out without solar irradiation and with the return air at ambient temperature.

In addition to the simulated values, experimental data from Tiddens et al. (2017) are included in the graph. These data were obtained without solar irradiation and with the return air at ambient temperature. A similar but much stronger trend compared to the current simulations can be seen.

The simulation results for the efficiency are presented in fig. 7 over the part load fraction $\left(\dot{Q}_{\text {inc }} / \dot{Q}_{\text {inc,design }}\right)$. A clear trend towards higher efficiencies with increasing load and decreasing hot air temperature can be identified. Maximum efficiencies range from $69.1 \%$ at $700{ }^{\circ} \mathrm{C}$ to $75.4 \%$ at $450{ }^{\circ} \mathrm{C}$. At a given temperature, the efficiency follows a power law with respect to the load resulting in a considerable reduction of the efficiency unter low part load conditions. At an air temperature of $700^{\circ} \mathrm{C}$ and $40 \%$ part load the simulation diverged because the prescribed mass flow distribution on the absorber surface could not be reached. This result is not surprising as the receiver is not designed for these high air temperatures at such low part load conditions.

The coefficients of the power law change with the hot air temperature. Therefore, the single regression for all data is more complex than for the air return ratio:

$$
\begin{aligned}
\eta=b_{0}+b_{1} \cdot T_{a b s}+b_{2} \cdot T_{a b s}^{2} & \\
& +\left(b_{3}+b_{4} \cdot T_{a b s}+b_{5} \cdot T_{a b s}^{2}\right) \cdot q^{-\left(b_{6}+b_{7} \cdot T_{a b s}\right)} .
\end{aligned}
$$

The coefficients of this regression are also listed in table 2. With this regression the average and maximum deviation from the simulated values is approximately $0.5 \%$ - points and $1.7 \%$ - points, respectively.

In addition, fig. 7 includes lines of constant massflow which are, according to eq. 7 , equivalent to a constant air return ratio. Due to the uncertainty of the regression in eq. 7 these lines cover a certain range of values of the efficiency and are therefore only 


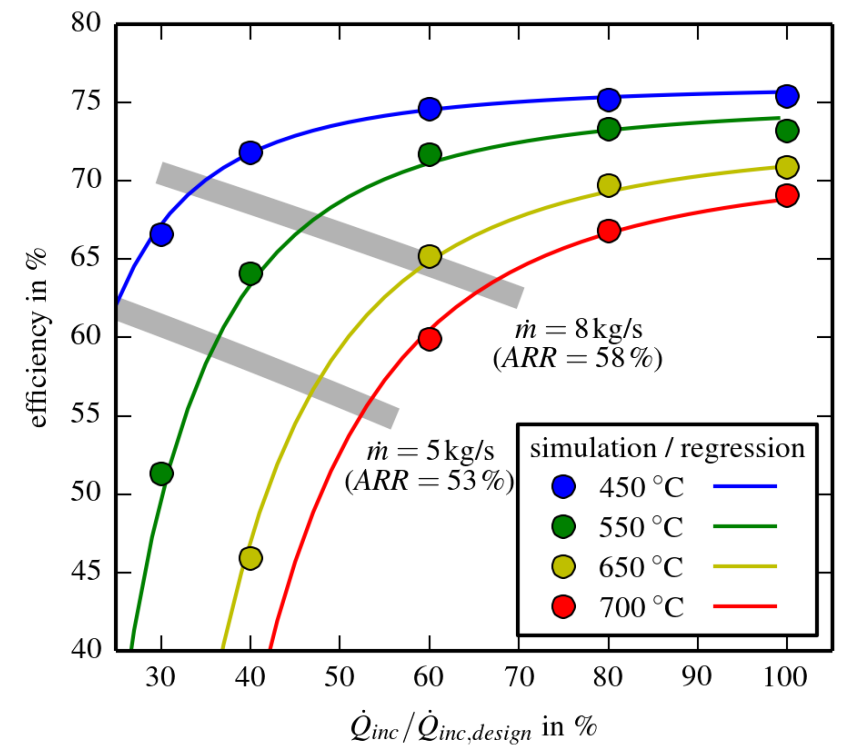

Figure 7: Simulation results and regression curves for the efficiency as a function of the part load condition with the hot air temperature as parameter. Ranges of equal mass flow are included for easier comparison to fig. 6 .

Table 2: Coefficients of the regressions in eqs. 7 and 8.

\begin{tabular}{lclc}
\hline coefficient & value & coefficient & value \\
\hline$a_{0}$ & $6.83 \times 10^{1}$ & $b_{2}$ & $-6.04 \times 10^{-7}$ \\
$a_{1}$ & $-6.72 \times 10^{1}$ & $b_{3}$ & $-1.25 \times 10^{-2}$ \\
$a_{2}$ & $9.02 \times 10^{-1}$ & $b_{4}$ & $7.53 \times 10^{-5}$ \\
& & $b_{5}$ & $-1.28 \times 10^{-7}$ \\
$b_{0}$ & $6.62 \times 10^{-1}$ & $b_{6}$ & 1.49 \\
$b_{1}$ & $4.92 \times 10^{-4}$ & $b_{7}$ & $2.22 \times 10^{-3}$ \\
\hline
\end{tabular}

of indicative nature.

The above presented numerical results have been compared to experimental data obtained at the solar tower Jülich. Experiments have been carried out in the summer of 2017 with the goal to obtain data with the newly developed flux measurement technique which can be used for performance estimations. The comparison of the numerical and the experimental data is given in table 3 . Five different settings are presented ranging from $22 \%$ partload to $44 \%$ partload and with hot air temperatures between $378^{\circ} \mathrm{C}$ and $592^{\circ} \mathrm{C}$. Due to constraints in the availability of the heliostatfield and due to poor weather conditions no higher load conditions could be tested. The values marked in bold have been used as boundary conditions for the CFD simulations. For the majority of the investigated cases the overestimation of the simulated efficiencies compared to the measurements is between $2 \%$ and $4 \%$ except for case 2 with a maximum of $9 \%$ while the difference between the hot air temperature lies between 6 (case 5) and $29 \mathrm{~K}$ (case 2). As described afore, the hot air temperature is measured at a point downstream compared to the point of evaluation in the simulation. Thus, higher hot air temperatures in the simulation are expected.

\section{Discussion}

The simulated results show a reasonable agreement with the measured values. As expected, higher values for the efficiency are obtained in the simulations because of the different definitions of the hot air temperature. Thus, the numerical model seems to be reasonably accurate for the estimation of receiver performance. Remaining differences between measurement and simulation can be attributed to several possible effects or to combinations thereof:

- Small fluctuations or drifts of the measured values during the measurement time as compared to fully stationary boundary conditions in CFD-simulations.

- Especially under part load conditions, where the efficiency strongly increases with the load, a small uncertainty in the flux measurement can lead to large deviations in the simulated efficiency.

- The simulations were carried out without considering ambient wind conditions.

The trend of an increasing air return ratio with increasing mass flow published earlier (Stadler et al., 2017) could be confirmed with the numerical simulations presented here. Where no intermediate values were measured in our previous study and only a linear trend for the investigated range could be assumed, it could now be shown, that the actual trend follows a power law. In the simulations the lower values at a mass flow rate of $5 \mathrm{~kg} / \mathrm{s}$ could be confirmed but the increase towards higher massflows turns out to be not as strong as suggested previously. This can at least in parts be attributed to the agglomerate discretisation in the simulations. From the grid study it could be seen, that a finer discretisation leads to higher $A R R$ values. Thus, these experiments support the assumption, the simulations rather underestimate the real air return ratio and thus efficiency.

Where only assumptions on the reason for the increase of the air return ratio with the mass flow could be made in our previous publication, the numerical simulation allows to analyse the phenomena more deeply. As can be seen in fig. 5, a high concentration of the return air can be seen especially at the upper end of the receiver. This return air is lost in the lower regions of the receiver and leads to a buffer layer of return air in the upper regions where it is sucked back in. With low mass flow rates, this buffer layer is much smaller so that it mixes more intensely with the ambient air resulting in lower return air concentrations and thus lower air return ratios at lower mass flows.

\section{Conclusion and Outlook}

A set of boundary conditions for CFD simulations has been developed which allows the simulation of the performance of open volumetric receivers according to the HiTRec principle. The model allows the inclusion of different absorber performance characteristics so that other absorber designs can be included as well. For the first time it is now possible to take into 
Table 3: Comparison of simulation results with experimental data obtained at the solar tower Jülich. Values marked in bold have been used as boundary condition or the CFD simulations.

\begin{tabular}{lcccccc}
\hline parameter & unit & $\begin{array}{c}\text { case } 1 \\
\exp / \text { CFD }\end{array}$ & $\begin{array}{c}\text { case } 2 \\
\exp / \text { CFD }\end{array}$ & $\begin{array}{c}\text { case } 3 \\
\exp / \text { CFD }\end{array}$ & $\begin{array}{c}\text { case } 4 \\
\exp / \text { CFD }\end{array}$ & $\begin{array}{c}\text { case } 5 \\
\exp / \text { CFD }\end{array}$ \\
\hline$\dot{Q}_{\text {inc }}$ & MW & $4.63 / \mathbf{4 . 6 3}$ & $4.34 / \mathbf{4 . 3 4}$ & $4.70 / \mathbf{4 . 7 0}$ & $5.02 / \mathbf{5 . 0 2}$ & $7.2 / \mathbf{7 . 2}$ \\
$\dot{m}$ & $\mathrm{~kg} / \mathrm{s}$ & $7.3 / \mathbf{7 . 3}$ & $6.5 / \mathbf{6 . 5}$ & $5.3 / \mathbf{5 . 3}$ & $5.6 / \mathbf{5 . 6}$ \\
$T_{\mathrm{r}}$ & ${ }^{\circ} \mathrm{C}$ & $129 / \mathbf{1 2 9}$ & $138 / \mathbf{1 3 8}$ & $115 / \mathbf{1 1 5}$ & $162 / \mathbf{1 6 2}$ & $80 / \mathbf{8 0}$ \\
$T_{\mathrm{h}}$ & ${ }^{\circ}$ & $517 / 527$ & $507 / 536$ & $592 / 601$ & $559 / 572$ & $378 / 384$ \\
$P_{\text {air }}$ & $\mathrm{MW}$ & $2.95 / 3.06$ & $2.51 / 2.73$ & $2.68 / 2.73$ & $3.05 / 3.13$ & $1.72 / 1.77$ \\
$\eta$ & $\%$ & $63.7 / 66.2$ & $57.8 / 63.0$ & $57.0 / 58.2$ & $60.6 / 62.2$ & $67.2 / 69.0$ \\
\hline
\end{tabular}

account the interaction between the absorber characteristics and the external flow around the entire receiver. Thereby the spatial distribution of the air return ratio, which is a key characteristic for the performance of open volumetric receivers, is simulated in detail. The model has been validated against newly obtained measurement data from the solar tower Jülich showing a general good agreement, whereby the simulation results are rather conservative estimations of the true air return ratio and efficiency. Depending on the hot air temperature the simulations show receiver efficiencies for the solar tower Jülich of $70.9 \%$ at $650{ }^{\circ} \mathrm{C}$ and $75.4 \%$ at $450{ }^{\circ} \mathrm{C}$.

The modeling approach allows for a comprehensive investigation of receiver performance under various boundary conditions such like varying wind conditions. Moreover, the model can also be used to analyse new large scale receivers and to estimate receiver performance for commercial applications of the open volumetric receiver.

\section{Acknowledgements}

This work was supported by the Federal Ministry for Economic Affairs and Energy on the basis of a decision by the German Bundestag, reference number 0324093B.

\section{References}

Ahlbrink, N., Alexopoulos, S., Andersson, J., Belhomme, B., Boura, C. T. Gall, J., Hirsch, T., 2009a. viCERP - the virtual institute of central receiver power plant. In: MATHMOD 2009 - 6th Vienna International Conference on Mathematical Modelling : February $11-13,2009$, Vienna, Austria. ARGESIM Report. No. 35.

Ahlbrink, N., Andersson, J., Diehl, M., Pitz-Paal, R., 2013. Optimization of the mass flow rate distribution of an open volumetric air receiver. Journal of Solar Energy Engineering 135 (4), 041003

Ahlbrink, N., Belhomme, B., Pitz-Paal, R., September 2009b. Transient simulation of solar tower power plant with open volumetric receiver. In: SolarPACES 2009.

URL http://elib.dlr.de/78438/

Ávila-Marín, A. L., 2011. Volumetric receivers in solar thermal power plants with central receiver system technology: A review. Solar Energy 85, 891910.

Capuano, R., Fend, T., Schwarzbözl, P., Smirnova, O., Stadler, H., Hoffschmidt, B., Pitz-Paal, R., May 2016. Numerical models of advanced ceramic absorbers for volumetric solar receivers. Renewable and Sustainable Energy Reviews 58, 656-665.

Capuano, R., Fend, T., Stadler, H., Hoffschmidt, B., Pitz-Paal, R., 2017. Optimized volumetric solar receiver: Thermal performance prediction and experimental validation. Renewable Energy 114, 556 - 566.
Christian, J. M., Ho, C. K., 2012. CFD simulation and heat loss analysis of the solar two power tower receiver. In: ASME 2012 6th International Conference on Energy Sustainability collocated with the ASME 2012 10th International Conference on Fuel Cell Science, Engineering and Technology. American Society of Mechanical Engineers, pp. 227-235.

Clausing, A., 1981. An analysis of convective losses from cavity solar central receivers 27 (4), 295-300.

Fend, T., Hoffschmidt, B., Pitz-Paal, R., Reutter, O., Rietbrock, P., 2004. Porous materials as open volumetric solar receivers: experimental determination of thermophysical and heat transfer properties. Energy 29 (5), 823-833.

Flesch, R., Stadler, H., Uhlig, R., Hoffschmidt, B., 2015. On the influence of wind on cavity receivers for solar power towers: An experimental analysis. Applied Thermal Engineering 87, 724-735.

Göhring, F., Bender, O., Röger, M., Nettlau, J., Schwarzbözl, P., 2011. Flux density measurement on open volumetric receivers. In: Proceedings of the SolarPACES Conference 2011.

Ho, C. K., Iverson, B. D., 2014. Review of high-temperature central receiver designs for concentrating solar power. Renewable and Sustainable Energy Reviews 29, 835-846.

Jang, H., Kim, T., Park, M., 2012. The first concentrating solar power project in Korea. In: Proceedings of the 18th SolarPACES Conference. p. 23826.

Koll, G., Schwarzbözl, P., Hennecke, K., Hartz, T., Schmitz, M., Hoffschmidt, B., 2009. The solar tower Jülich - a research and demonstration plant for central receiver systems. In: Proceedings of the 15th SolarPACES Conference.

Maldonado Quinto, D., 2016. Konvektive Verluste an offenen volumetrischen Solarstrahlungsempfängern. Ph.D. thesis, RWTH Aachen, in German.

Marcos, M. J., Romero, M., Palero, S., 2004. Analysis of air return alternatives for CRS-type open volumetric reciever. Energy 29, 677-686.

Pitot de la Beaujardiere, J.-F. P., Reuter, H. C., 2018. A review of performance modelling studies associated with open volumetric receiver CSP plant technology. Renewable and Sustainable Energy Reviews 82, 3848 - 3862.

Roldán, M., Fernández-Reche, J., Ballestrín, J., jan 2016. Computational fluid dynamics evaluation of the operating conditions for a volumetric receiver installed in a solar tower 94, 844-856.

Siebers, D. L., Kraabel, J. S., April 1984 1984. Estimating convective energy losses from solar central receivers. Tech. rep., Sandia National Laboratories.

Siegrist, S., Stadler, H., Hoffschmidt, B., 2018. Wind tunnel measurements of forced convective heat loss from multi-megawatt cavities of solar central receiver systems. Solar Energy.

Stadler, H., Tiddens, A., Schwarzbözl, P., Göhring, F., Baumann, T., Trautner, J., 2017. Improved performance of open volumetric receivers by employing an external air return system. Solar Energy 155, 1157 - 1164.

Tiddens, A., Röger, M., Stadler, H., Hoffschmidt, B., April 2017. Air return ratio measurements at the solar tower Jülich using a tracer gas method. Solar Energy 146, 351-358.

Uhlig, R., Frantz, C., Fritsch, A., 2016. Effects of vertically ribbed surface roughness on the forced convective heat losses in central receiver systems. AIP Conference Proceedings 1734 (1), 030036.

Wu, Z., Caliot, C., Flamant, G., Wang, Z., 2011. Coupled radiation and flow modeling in ceramic foam volumetric solar air receivers. Solar Energy 85 (9), 2374-2385

Wu, Z., Wang, Z., 2013. Fully coupled transient modeling of ceramic foam volumetric solar air receiver. Solar Energy 89, 122-133. 